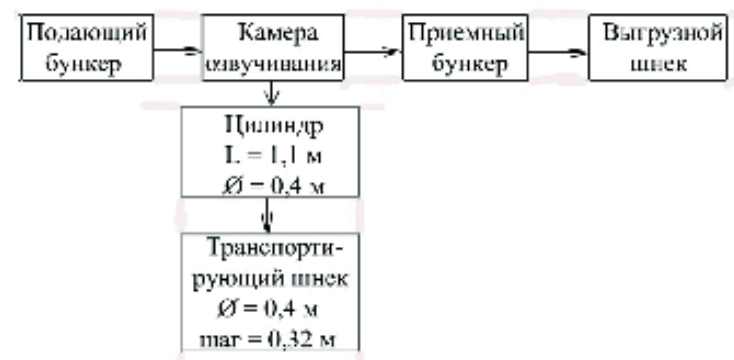

Рис. 4. Схема конструкиии установки для ультразвуковой подготовки зерна к помолу

\section{СПИСОК ЛИТЕРАТУРЫ}

1. Акопян В.Б., Ершов Ю.А. Основы взаимодействия ультразвука с биологическими объектами. - М., $200.5-224$ c.

2. Егоров, Г.А. Управление техническими средствами зерна. - Воронеж, 2000. - 348 с.

3. Особенности подготовки зерна к помолу / Ф.Я. Рудик [и др.] // Актуальные проблемы ветеринарной медицины и пищевых технологий: материалы
Междунар. науч.-практ. конф. - Саратов: Наука. C. $150-154$.

4. Рудик Ф.Я., Морозов А.А., Семилет Н.А. Очистка и увлажнение зерна в ультразвуковом поле // Научное обозрение. - 2016. - № 2. - С. 22-29.

5. Ультразвуковая обработка зерна при подготовке к помолу / Ф.Я. Рудик [и др.] // Хранение и переработка сельхозсырья. - 2016. - № 2. - С. 53-56.

Рудик Феликс Яковлевич, $\partial-p$ техн. наук, проф. кафедры «Технологии продуктов питания», Саратовский государственный аграрный университет имени Н.И. Вавилова

Моргунова Наталья Львовна, канд. с.-х. наук, доцент кафедры «Технологии продуктов питания», Саратовский государственный аграрный университет имени Н.И. Вавилова

Семилет Никита Александрович, учебный мастер учебно-производственного комбината питания, Саратовский государственный аграрный университет имени Н.И. Вавилова

410005, г. Саратов, ул. Соколовая, 335.

Тел.: (8452) 69-29-65.

Ключевые слова: зерно; мука; помол; ультразвук; ультразвуковая установка.

\title{
INTENSIFICATION OF PREPARATION for GRAIN milling
}

Rudik Felix Yakovlevich, Doctor of Technical Sciences, Professor of the chair "Food Technology", Saratov State Agrarian University named after N.I. Vavilov. Russia.

Morgunova Natalia Lvovna, Candidate of Agricultural Sciences, Associate Professor of the chair "Food Technology", Saratov State Agrarian University named after N.I. Vavilov. Russia.

SEMILET Nikita Alexandrovich, Training Master of the training and production of the power plant, Saratov State Agrarian University named after N.I. Vavilov. Russia.

Keywords: grain; flour; grind; ultrasound; ultrasonic device.
In this work the actual scientific and production task of increase of efficiency of preparation of grain for simple grinding is solved. This is done by wet cleaning the surface from dirt and insects. Is the achievement of optimum grinding condition parameters with the intensification of the process of ultrasonic vibrations. Analytically and experimentally investigated and installed structural-regime parameters of the ultrasonic plant and technology for cleaning and courage of grain. The authors consider the regularities of the influence of structural and regime parameters on the intensity of grain processing in an ultrasonic plant.

удк 620.192.6

\section{ФИЗИКО-МАТЕМАТИЧЕСКАЯ МОДЕЛЬ МЕХАНИЗМА УПРОЧНЕНИЯ ГАЛЬВАНИЧЕСКИХ ПОКРЫТИЙ НАНОРАЗМЕРНЫМИ МАТЕРИАЛАМИ}

\author{
САФОНОВ Валентин Владимирович, Саратовский государственный аграрный университет \\ имени Н.И. Вавилова \\ ШИШУРИН Сергей Александрович, Саратовский государственный аграрный университет \\ имени Н.И. Вавилова \\ ЧУМАКОВА Светлана Валентиновна, Саратовский государственный аграрный университет \\ имени Н.И. Вавилова
}

ГОРБУшин Павел Александрович, Саратовский государственный аграрный университет имени Н.И. Вавилова

Предложена физико-математическая модель механизма упрочнения гальванических покрытий наноразмерными материалами. Установлено, что на механизм упрочнения наибольшее влияние оказывают структурные превращения, происходящие в нанокомпозищионых покрытиях. Исходя из физических процессов, происходящих в гальванических покрытиях при модификации их наноразмерными материалами, была обоснована и исследована физико-математическая модель механизма их упрочнения. Представленная модель позволяет прогнозировать степенъ упрочнения нанокомпозиционных покрытий в зависимости от используемых нанодисперсных материалов и расстояния между ними в покрытии.

Введение. В настоящее время для повышения надежности технических объектов и их агрегатов используется нанесение на рабочие поверхности их ресурсоопределяющих деталей нанокомпозиционных гальванических покрытий (НКГП).
Микротвердость таких покрытий определяется наличием и концентрацией в них различных дефектов. При этом важно учитывать характер взаимодействия дефектов, образующихся под влияниемразличныхвнешнихвоздействий.Извест- 
но $[2,6]$, что воздействуя на гальваническое покрытие, можно целенаправленно изменять систему его структурных дефектов, а следовательно, и его микротвердость. Одно из таких воздействий модификация гальванических покрытий наноразмерными частицами (НЧ). Особенность этой технологии заключается в том, что вместе с металлом из гальванической ванны на детали осаждаются частицы, волокна и усы различных карбидов, боридов, оксидов, сульфидов, порошков полимеров и т.д. Уникальные свойства таких частиц широко описаны в литературе $[1,2,6]$. Использование наночастиц в гальванических покрытиях позволяет изменять их микротвердость $[8,9]$ благодаря перераспределению дефектов, таким образом, большой научно-практический интерес представляет изучение механизма упрочнения НКГП.

Цель исследования - объяснить механизм повышения микротвердости гальванических покрытий в результате модификации их наноразмерными частицами можно теорией дислокаций и препятствий [2].

Методика исследований. Как известно [5], в гальванических покрытиях образуется большое количество дефектов, таких как вакансии, внедренные атомы и дислокации. При этом значительное влияние на микротвердость материалов оказывают дислокации.

Важное свойство дислокации - это возможность ее перемещения [4]. Дислокации способны двигаться по плоскостям скольжения в кристаллической решетке под действием весьма малых напряжений сдвига. При перемещении дислокаций через решетку в каждый момент этого движения нарушаются связи лишь ограниченного количества атомов, расположенных непосредственно в местах нахождения дислокаций. Следовательно, упрочнение гальванических покрытий может быть достигнуто либо устранением дислокаций, либо созданием сопротивления их движению [5].

Полностью устранить дислокации не представляется возможным вследствие того, что растущие при кристаллизации зерна будут повернуты друг к другу под небольшим углом и при сращивании кристаллов на границе их раздела неизбежно образуются дислокации. Тогда упрочнение гальванических покрытий будет напрямую зависеть от сопротивления движению дислокаций.

Одним из перспективных способов создания сопротивления движению дислокаций в гальванических покрытиях является модификация их наноразмерными частицами.

При встрече с наночастицами, находящимися в покрытии, скользящие дислокации будут огибать препятствия и оставлять на них замкнутые петли (рис. 1) [3].

При прохождении последующих скользящих дислокаций между наноразмерными частицами они оставят вокруг новые петли большего разме- ра. Прохождение каждой из последующих дислокаций между наночастицами будет более затруднено, в результате чего повысится плотность дислокаций и, как следствие, микротвердость композиции $[1,2]$. Таким образом, упрочняющий эффект от воздействия дислокаций проявляется вокруг каждой НЧ на расстоянии равном диаметру $\left(d_{\text {дп }}\right)$ дислокационной петли, образованной от последней прошедшей между частицами дислокации (см. рис. 1, поз. 3).

При рассмотрении влияния наночастиц на модифицируемое гальваническое покрытие нельзя забывать о структурных изменениях в нем. Исследования, проведенные авторами $[1,2,6,7,10]$, показали, что наночастицы способствуют уменьшению размеров зерна покрытия (см. рис. 1, поз. 4), вследствие чего происходит уплотнение матрицы и, как следствие, повышение микротвердости всей композиции. Упрочняющий эффект от измельчения зерна распространяется на все покрытие. Так как нанодисперсные частицы являются центрами кристаллизации гальванического покрытия, то наименьший размер будут иметь зерна, расположенные вблизи нанодисперсных частиц, и по мере удаления от них размер зерна будет увеличиваться. Данный упрочняющий эффект будет усиливаться упрочняющим эффектом от дислокационных петель, а также оказывать влияние на расстояния $l_{\text {Р3 }}$ (см. рис. 1 ).

Таким образом, на механизм упрочнения НКГП влияюет не только микротвердость наночастиц и образование вокруг них дислокационных петель, но и уменьшение размеров зерна нанокомпозиционного покрытия.

Результать исследований. Описанные выше процессы дают основание полагать, что механизм упрочнения НКГП в основном определяется двумя стадиями и схематично может быть представлен в виде физико-математической мо-

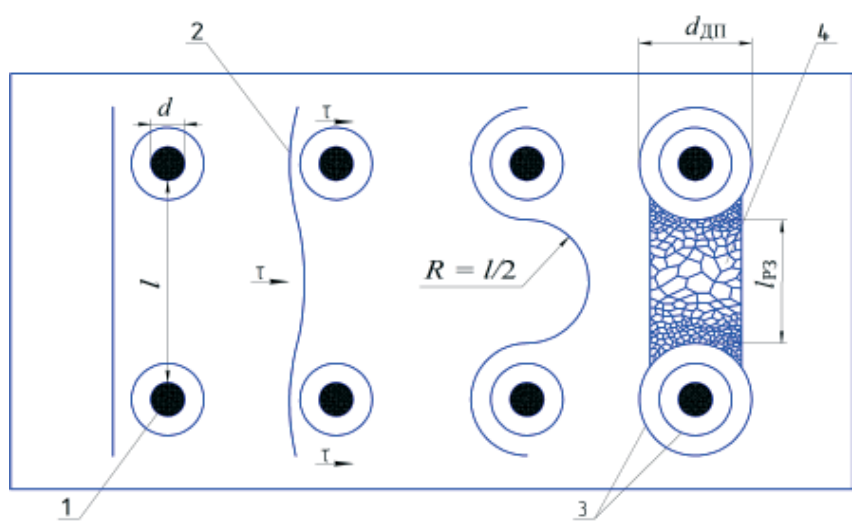

Рис. 1. Схема процесса формирования дислокационных петель в матрице: 1 - наночастица; 2 - линии дислокаций; 3 -дислокационные петли; 4 - участок упрочнения вследствие уменъшения зерна НКГП; $d$ - диаметр наноразмерной частищъ; $d_{\text {дп }}$ диаметр дислокационной петли; $l$ - расстояние между соседними НЧ; $l_{\text {р3 }}$ - длина участка упрочнения только вследствие уменьшения зерна НКГП; $\tau$ - направление действия касательных напряжений 
дели (рис. 2). Ее использование такой модели позволит установить зависимость микротвердости НКГП от расстояния между нанодисперсными частицами в покрытии.

Представленную модель будем рассматривать как систему последовательных независимых линейных процессов, а значит, логично говорить о линейности системы в целом. Результирующий эффект линейных процессов можно проанализировать при рассмотрении отдельных этапов их графического представления.

На основании предложенной схемы зависимость микротвердости НКГП от расстояния между НЧ можно описать функцией

$$
H=f(S) \text {. }
$$

Так как данная функция (1) показывает зависимость микротвердости нанокомпозиционного гальванического покрытия от расстояния между наночастицами, соответствующего интервалу $\left[S_{1} ; S_{2}\right]$ :

$$
S_{2}-S_{1}=l,
$$

то с уменьшением шага $l$ микротвердость покрытия увеличивается.

Исследование свойств функции (1) позволяет с физико-математической точки зрения описать механизм упрочнения нанокомпозиционного покрытия.

Используем аналитическое представление схемы (см. рис. 2) следующей формулой:

$$
\frac{H-H_{0}}{H_{1}-H_{0}}=\frac{S-S_{0}}{S_{1}-S_{0}}
$$

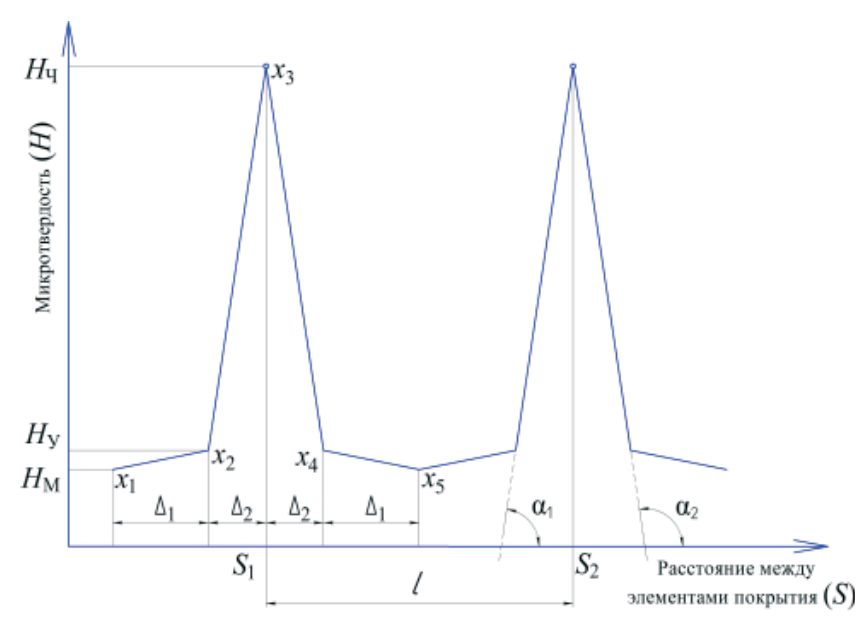

Рис. 2. Схема к построению физикоматематической модели механизма упрочнения НКГП: $H_{ч}$ - микротвердость НЧ; $H_{\mathbf{y}}-$ микротвердость упрочнения НКГП от влияния уменьшения размера зерна; $H_{M}-$ микротвердость гальванического покрытия без НЧ; $l$ - расстояние между наночастицами; $S_{1}, S_{2}-$ координаты по оси $S$ любой наночастищы в покрытии; $\Delta_{1}, \Delta_{2}-$ приращения по оси $S$, показывающие удаленность от НЧ в покрытии; $\alpha_{1}, \alpha_{2}$ - углы наклона прямых; $x_{1}, x_{2}, x_{3}, x_{4}, x_{5}$ - точки пересечения прямых где $H_{0}, H_{1}, S_{0}, S_{1}$ - координаты точек, принадлежащих соответствующим прямым.

Подставляя координаты известных точек в уравнение (3), получим систему уравнений, описывающую пересекающиеся прямые на рис. 2:

$$
\begin{gathered}
\left(x_{1}, x_{2}\right): \lambda_{1} S+\mathrm{M}_{1} H+3_{1}=0, \quad S \in\left[S_{1}-\left(\Delta_{1}+\Delta_{2}\right) ; S_{1}-\Delta_{2}\right] ; \\
\left(x_{2}, x_{3}\right): H-H_{0}=\operatorname{tg} \alpha_{1}\left(S-S_{0}\right), \quad S \in\left[S_{1}-\Delta_{2} ; S_{1}\right] ; \\
\left(x_{3}, x_{4}\right): H-H_{0}=\operatorname{tg} \alpha_{2}\left(S-S_{0}\right), \quad S \in\left[S_{1} ; S_{1}+\Delta_{2}\right] ; \\
\left(x_{4}, x_{5}\right): \pi_{2} S+\mathrm{M}_{2} H+3_{2}=0, \quad S \in\left[S_{1}+\Delta_{2} ; S_{1}+\left(\Delta_{1}+\Delta_{2}\right)\right] .
\end{gathered}
$$

где $\lambda_{1}, \mu_{1}$ - координаты вектора, ортогонального прямой $\left(x_{1} ; x_{2}\right) ; \eta_{1}-$ коэффициент, определяющий расположение прямой $\left(x_{1} ; x_{2}\right)$ относительно оси микротвердости; $\lambda_{2}, \mu_{2}-$ координаты вектоpa, ортогонального прямой $\left(x_{4} ; x_{5}\right) ; \eta_{2}-$ коэффициент, определяющий расположение прямой $\left(x_{4}\right.$; $x_{5}$ ) относительно оси микротвердости.

Схема (см. рис. 2), описываемая формулой (1), является периодической. Ее период

$$
\sigma=2\left(\Delta_{1}+\Delta_{2}\right)
$$

При рассмотрении функции (1) на интервале $\left[S_{1}-\left(\Delta_{1}+\Delta_{2}\right) ; S_{1}+\left(\Delta_{1}+\Delta_{2}\right)\right]$, можно отметить, что она является возрастающей $\forall S$, если $S \in\left[S_{1}-\left(\Delta_{1}+\Delta_{2}\right) ; S_{1}-\Delta_{2}\right]$ и $S \in\left[S_{1}-\Delta_{2} ; S_{1}\right]$, то есть

при приближении к точке $\left(S_{1} ; H\right)$, и убывающей $\forall S$, если $\left.S \in\left[S_{1} ; S_{1}+\Delta_{2}\right)\right]$ и $S \in\left[S_{1} ; S_{1}+\left(S_{1}+\Delta_{2}\right)\right]$.

Заключение. В ходе исследования установлено, что на механизм упрочнения НКГП наибольшее влияние оказывают дислокационные петли, образующиеся вокруг нанодисперсных частиц и измельчение зерна покрытия в процессе его кристаллизации. Исходя из схематического представления физического процесса, можно говорить о линейной зависимости повышения микротвердости НКГП от увеличения расстояния между наночастицами. Представленные зависимости позволяют прогнозировать степень упрочнения НКГП от концентрации в нем наночастиц.

\section{СПИСОК ЛИТЕРАТУРЫ}

1. Антропов Л.И., Лебединский Ю.Н. Композиционные электрохимические покрытия. - Киев: Техника, 1989. - 200 c.

2. Бородин И.Н. Упрочнение деталей композиционными покрытиями. - М.: Машиностроение, 1982. $141 \mathrm{c.}$

3. Гегузин Я.Е., Кривоглаз М.А. Движение макроскопических включений в твердых телах. - М.: Металлургия, 1971. - 344 с.

4. Горшков В.С., Савельев В.Г., Федоров Н.Ф. Физическая химия силикатов и других тугоплавких соединений. - М.: Высш. шк. - 1988. - 400 с.

5. Поляк M. С. Технология упрочнения // Техноло- 
гические методы упрочнения: в 2 т. - М.: Машиностроение, 1995. - Т. 2. - 668 с.

6. Сайфуллин Р.С. Композиционные покрытия и материалы. - М.: Химия.1977. - 272 с.

7. Сафонов В.В., Александров В.А., Шишурин С.А., Азаров А.С. Применение наноматериалов при техническом сервисе автотракторной техники // Вестник Федерального государственного образовательного учреждения высшего профессионального образования Московский государственный агроинженерный университет им. В.П. Горячкина. - 2009. - № 3. - С. 62-66.

8. Сафонов В.В., Шишурин С.А., Годунов Н.Б., Семочкин В.С. Нанокомпозиционные никель-фосфорные покрытия с улучшенными эксплуатационными свойствами // Вестник Саратовского госагроуниверситета им. Н.И. Вавилова. - 2011. - № 12. - С. 56-58.

9. Шишурин С. А., Семочкин В. С., Сафонов В. В., Гурьев А. Е. Структура и физико-механические свойства композиционных гальванохимических покрытий // Вестник АПК Ставрополя. - 2014. - № 3 (15). C. $77-80$.

10. Safonov V.V., Shishurin S.A., Semochkin V.S., Zakharevich A.M. Effect of alumina nanoparticles on the structure and physicochemical properties of chromium coatings // Surface Engineering and Applied Electrochemistry.
2015. T. 51. № 6. С. 517-522.

Сафонов Валентин Владимирович, $\partial-p$ техн. наук, проф., зав. кафедрой «Технический сервис и технология конструкционных материалов», Саратовский государственный аграрный университет имени Н.И. Вавилова. Россия.

Шишурин Сергей Александрович, канд. техн. наук, доцент кафедры «Технический сервис и технология конструкиионных материалов», Саратовский государственный аграрный университет имени Н.И. Вавилова. Россия.

Чумакова Светлана Валентиновна, канд. техн. наук, доцент кафедры «Математика и математическое моделирование», Саратовский государственный аграрный университет имени Н.И. Вавилова. Россия.

Горбушин Павел Александрович, ассистент кафедры «Технический сервис и технология конструкционных материалов», Саратовский государственный аграрный университет имени Н.И. Вавилова. Россия.

410056, г. Саратов, ул. Советская, 60.

Тел.: (8452) 74-96-56.

Ключевые слова: композиционные покрытия; гальванические покрытия; нанодисперные частицы; надежность; степень упрочнения; микротвердость; дислокации; структура материала.

\title{
PHYSICO-MATHEMATICAL MODEL OF THE MECHANISM OF GALVANIC COATINGS BY NANOSCALE MATERIALS
}

Safonov Valentin Vladimirovich, Doctor of Technical Sciences, Professor, Head of the chair "Technical Service and Technology of Structural Materials", Saratov State Agrarian University named after N.I. Vavilov. Russia.

Shishurin Sergey Aleksandrovich, Candidate of Technical Sciences, Associate Professor of the chair "Technical Service and Technology of Structural Materials", Saratov State Agrarian University named after N.I. Vavilov. Russia.

Chumakova Svetlana Valentinovna, , Candidate of Technical Sciences, Associate Professor of the chair "Mathematics and Mathematical Modeling" of the Saratov State Agrarian University named after N.I. Vavilov. Russia.

Gorbushin Pavel Aleksandrovich, Assistant of the chair "Technical Service and Technology of Structural Materials", Saratov State Agrarian University named after N.I. Vavilov. Russia.
Keywords: composite coatings; galvanic coatings; nanodispersed particles; reliability; degree of hardening; microhardness; dislocations; material structure.

The article proposes a physico-mathematical model of the mechanism of hardening of galvanic coatings by nanoscale materials. It has been established that the mechanism of hardening is most strongly influenced by structural transformations occurring in nanocomposite coatings. Based on the physical processes taking place in modified by nanoscale materials galvanic coatings, the physico-mathematical model of the mechanism of their hardening was substantiated and investigated. The presented model allows predicting the degree of hardening of nanocomposite coatings depending on the nanodispersed materials and the distance between them in the coating.

Удк 631.532.2+631.331.072.3

\section{СХЕМА ПРОЦЕССА ОБРАЗОВАНИЯ ВАЛКА ЛУКА-СЕВКА НА СФОРМИРОВАННОМ ЛОЖЕ ПРИ МЕХАНИЗИРОВАННОЙ УБОРКЕ}

\author{
СИБИРЁВ Алексей Викторович, Федеральный научный агроинженерный центр ВИМ \\ АКСЕНОВ Александр Геннадьевич, Федеральный научный агроинженерный центр ВИМ \\ дОРОХОВ Алексей Семенович, Федеральный научный агроинженерный центр ВИМ
}

Теоретически определен технологический процесс образования валка лука-севка при его механизированной уборке. Определены возможные варианты расположения луковиц, лука-севка в валке, объемы, занимаемые луковицами в валке, величина смятия объема почвы катком-ложеобразователем лукоуборочной машины, плотность почвы после ее деформации катком-ложеобразователем лукоуборочной машины.

Введение. При формировании валка лукасевка на поверхности поля лукоуборочной машиной луковицы взаимодействуют друг с другом и с поверхностью почвы [3-7]. В процессе извлечения луковиц из почвы лукоуборочная машина движется поступательно, что препятствует образованию на поверхности поля валка лука-севка большой высоты и тем самым увеличивается число поврежденных луковиц (так как в результате увеличения валка высота падения луковиц и 